\title{
Identification of clinical, epidemiological and laboratory risk factors for leprosy reactions during and after multidrug therapy
}

\author{
Douglas Eulálio Antunes, Sergio Araujo/ ${ }^{+}$, Gabriela Porto Ferreira, \\ Ana Carolina Sousa Rodrigues da Cunha, Adeilson Vieira da Costa, \\ Maria Aparecida Gonçalves, Isabela Maria Bernardes Goulart \\ Centro de Referência Nacional em Hanseníase/Dermatologia Sanitária, Hospital de Clínicas, \\ Faculdade de Medicina, Universidade Federal de Uberlândia, Uberlândia, MG, Brasil
}

\begin{abstract}
This cross-sectional retrospective study evaluated 440 leprosy patients; 57\% (251/440) had leprosy reactions during and/or after multidrug therapy, 80.5\% (202/251) of whom presented with multibacillary leprosy. At diagnosis, positive bacterial index (BI) [odds ratio $(O R)=6.39 ; 95 \%$ confidence interval (CI): 4.1-10.1)] or polymerase chain reaction (PCR) $(O R=9.15$; 95\% CI: 5.4-15.5) in skin smears, anti-phenolic glycolipid-1 (anti-PGL-1) ELISA (OR = 4.77; 95\% CI: 2.9-7.9), leucocytosis (OR = 9.97; 95\% CI: 3.9-25.7), thrombocytopenia (OR $=5.72$; 95\% CI: 2.3-14.0) and elevated lactate dehydrogenase $(O R=2.38 ; 95 \%$ CI: 1.4-4.0) were potential markers for the development of reactions during treatment. After treatment, positive BI (OR $=8.47 ; 95 \% \mathrm{CI}$ : 4.7-15.3) and PCR (OR $=6.46 ; 95 \%$ CI: 3.4-12.3) in skin smears, anti-PGL-1 ELISA (OR =2.25; 95\% CI: 1.3-3.9), anaemia (OR =2.36; 95\% CI: 1.2-4.5), leucocytosis $(O R=4.14 ; 95 \%$ CI: 1.5-11.6) and thrombocytopenia $(O R=3.70 ; 95 \%$ CI: 1.3-2.2) were risk factors for the occurrence of reactions during the study period. The identification of groups with an increased risk for developing reactions will allow for the timely development of a treatment plan to prevent nerve damage and, therefore, the appearance of the disabling sequelae associated with the stigma of leprosy.
\end{abstract}

Key words: leprosy - epidemiology - tropical medicine - infectious diseases

Leprosy, caused by Mycobacterium leprae, is a disease that primarily affects the skin and peripheral nerves, leading to loss of sensory, motor and autonomic functions. Despite the existence of the highly effective multidrug therapy (MDT) against leprosy, which is a primary factor associated with the cure of this disease, difficulties persist in the clinical management, treatment and monitoring of leprosy reactions, which can lead to nerve damage (Lockwood \& Suneetha 2005).

Brazil has the second highest prevalence of leprosy in the world; even with a continuing decline in the annual incidence, since 2004, 33,955 new cases of leprosy were detected in Brazil in 2011 (WHO 2012).

Leprosy reactions may occur before, during and after MDT treatment and are classified as type 1 or type 2 reactions (Lockwood et al. 2011). The type 1 reaction, or reversal reaction, is associated with T-helper (Th)1 cellmediated immunity, characterised by granuloma expansion, oedema, recruitment of $\mathrm{CD}^{+}$lymphocytes, an increase in interleukin (IL)-2 receptors and expression of receptors to human leukocyte antigens-D in the cellular infiltrate. A type 1 reaction is also characterised by the presence of interferon-gamma and tumour necrosis factor alpha (TNF- $\alpha$ ), which are important for the expres-

doi: $10.1590 / 0074-0276130222$

Financial support: FAPEMIG, CNPq, CAPES, FNS/MS

+ Corresponding author: sergiooxwide@hotmail.com

Received 24 April 2013

Accepted 16 August 2013 sion of the inducible nitric oxide synthase enzyme and are responsible for the efficient activity of macrophages (Goulart et al. 2002).

The type 2 reaction, also referred to as erythema nodosum leprosum, is a systemic hypersensitivity reaction that resembles the type III reaction of Coombs and Gell's classification and is associated with immune complex deposition in tissues that is enhanced by increases in blood pressure and vascular permeability. It is also related to elevated TNF- $\alpha$ levels, neutrophil infiltration, activation of the complement system compromising several organs and elevated levels of IL-6, IL-8 and IL-10 messenger ribonucleic acid tissue expression, which characterise the Th2-type auxiliary T cell immune response, namely, humoral immunity (Naafs 1994).

The presence of infections (bacterial, fungal or viral), use of iodide, bromide, ofloxacin, rifampin or dapsone-based medication, hormonal alterations, pregnancy, postpartum, breastfeeding, alcohol use, trauma, vaccination, surgical procedures and physical stress have been mentioned as risk factors for leprosy reactions (Scollard et al. 1994). Oral infections have also been suggested as risk factors for the occurrence of leprosy reactions, as indicated by an observed reduction in the rates of reactions after the establishment of dental treatment (Motta et al. 2011). After treatment, an elevated titre of circulating anti-phenolic glycolipid-1 (anti-PGL-1) IgM antibodies has been identified as a relevant marker for a reaction; seropositivity at MDT discharge corresponded to a 10-fold higher probability for the development of a reaction compared with that in patients with negative results (Brito et al. 2011). 
Regarding exclusively type 1 reactions, patients with a single lesion that were older than 40 years or had positive polymerase chain reaction (PCR) results for the detection of $M$. leprae DNA in skin biopsies have been found to be at greater risk for the occurrence of reactions (Sousa et al. 2007).

This study investigated the clinical, epidemiological and laboratory risk factors for the development of leprosy reactions during and after MDT to identify potential risk groups and to promote improvements in the prevention, treatment and monitoring of leprosy reactions, thereby preventing nerve damage and, thus, the appearance of impairments.

\section{SUBJECTS, MATERIALS AND METHODS}

Type of study and population sample - In this crosssectional observational study, the total sample was subdivided into two groups: patients affected by leprosy reactions during or after treatment and patients without leprosy reactions at any time. The sample consisted of 440 leprosy patients diagnosed by a committee of leprosy experts based on clinical and laboratory tests and classified according to the clinical presentation and operational classification.

Data collection - Clinical, epidemiological and laboratory data from secondary sources (medical records) were gathered using a data collection form that included stratified fields for the allocation of potential risk factors for the occurrence of leprosy reactions during and after treatment. The variables considered were as follows: clinical and operational classification, gender, age, ethnic group, bacterial index (BI), PCR for the detection of M. leprae DNA, anti-PGL-1 ELISA serology, intradermal Mitsuda test results, complete blood count deviations from reference values (Lewis et al. 2001) and biochemical blood test [glucose, bilirubin, aspartate transaminase, alanine transaminase (ALT), gamma-glutamyl transferase, alkaline phosphatase, lactate dehydrogenase (LDH), sodium, potassium, urea and creatinine] deviations from reference values (Schumann et al. 2002, ADA 2011).

Inclusion and exclusion criteria - This study included patients diagnosed with leprosy who were treated with the MDT regimen at the National Reference Centre for Leprosy and Sanitary Dermatology from the period of January 2002-December 2009 and who had at least one year of follow-up after a medication discharge as described in their medical records. All patients with incomplete medical records, alternative medications and/or changes in dose-related MDT adverse effects (anaemia and thrombocytopenia), as well as those with leprosy reactions at diagnosis and discharge were excluded from the study.

Clinical and operational classification criteria - The leprosy patients were diagnosed by a committee of leprosy experts based on clinical and laboratory tests and were stratified according to Ridley-Jopling's clinical classification (Ridley \& Jopling 1966). For treatment purposes, all patients received an operational classification of paucibacillary (PB) or multibacillary (MB) leprosy, based on the World Health Organization criteria and ancillary laboratory tests. Patients with less than five lesions, negative results for smears at any site, negative results for ELISA anti-PGL-1 and PCR in skin smears and biopsies were classified as PB; patients with more than five lesions, positive results for smears at any site or positive results for ELISA anti-PGL-1 and PCR in skin smears and biopsies were classified as MB.

Criteria for definition of leprosy reactions - The leprosy reactions (type 1 and 2) were identified and classified in the medical records after a confirmed diagnosis by the expert leprosy physician who attended to the patient during the clinical episode. To determine the number of reactions, the exacerbation of symptoms seven days or more after completion of the reaction treatment (prednisone or thalidomide) was considered to be a new reaction and symptoms that emerged in less than seven days after completion of treatment were considered to be a continuation of the previous reaction.

Statistical analysis - Logistic regression analysis was applied to determine the degree of dependence between the independent and dependent epidemiological variables. The probability of a leprosy reaction occurring during or after treatment given the presence of a specific factor was measured by calculating the odds ratio (OR), along with the associated confidence intervals (CI) and $p$ values. The Spearman correlation was used to verify the degree of association between two variables. All analyses were conducted with the software BioEstat 5.0 (open licence). Hypotheses were tested at a significance level of 0.05 .

Ethics - The study was approved by the Ethical Committee on Human Research of the Federal University of Uberlândia under registration 449/10 and protocol 193/10. The ethical principles stated in Resolution 466/2012 of the Brazilian National Council of Health underlie the study methodology.

\section{RESULTS}

Among the 665 medical records scanned, 33.8\% $(225 / 625)$ were excluded for the following reasons: $10.2 \%(68 / 665)$ of the patients transferred to other health care facilities, 9.3\% (62/665) of the patients presented with leprosy reactions at diagnosis or before the collection of samples, $5.2 \%(35 / 665)$ of the patients presented with leprosy reactions at discharge or at the time of the collection of samples after treatment, 5.5\% (37/665) of the patients were taking alternative medications and/or had changes in doses related to MDT adverse effects (anaemia and thrombocytopenia) and 3.4\% (23/665) had incomplete medical records.

Of the $66.2 \%(440 / 665)$ of the patients who had complete medical records and did not present leprosy reactions at diagnosis and/or discharge, 57\% (251/440) presented reactions during and/or after MDT treatment and $43 \%(189 / 440)$ did not present reactions at any time.

Table I displays the frequency of the epidemiologic characteristics stratified into the two groups of patients with and without leprosy reactions and the results of the logistic regression analysis. 
Leprosy reactions occurred primarily in patients classified as MB (80.5\%, 202/251), MB patients had an increased probability of having a leprosy reaction compared with all non-MB patients $(\mathrm{CI}=3.59-9.82$, $\mathrm{p}$ $<0.001)$. Regarding the clinical classification of the patients with a leprosy reaction, there was a predominance of borderline-tuberculoid (BT) patients $(33.9 \%, 85 / 251)$ followed by lepromatous (LL) patients $(24.3 \%, 61 / 251)$.

Although the OR of a leprosy reaction were significantly higher for males than for females $(\mathrm{CI}=1.22$ $3.32, \mathrm{p}=0.006$ ), it should be noted that among male patients presenting reactions, $68.8 \%(139 / 202)$ had MB leprosy, while among females, only $31.2 \%$ had MB leprosy $(63 / 202)$. When considering ethnicity, the Caucasian phenotype prevailed in the reactive group $(53.4 \%$, 134/251), with a statistically significant increase in the OR of a reaction compared with all other ethnic groups.

The stratified descriptive analysis of the patients with leprosy reactions is presented in Table II. A total of $47.9 \%(211 / 440)$ of the patients presented reactions during treatment; $64.5 \%(136 / 211)$ of the reactions were type 1 and $35.1 \%(74 / 211)$ were classified as BT. In the reaction group, $73.5 \%(155 / 211)$ developed reactions during the first three months of MDT treatment and
92.8\% (196/211) developed reactions up to nine months after the initiation of treatment. In the period after the end of MDT treatment, 32.9\% (52/158) presented reactions up to three months following discharge, $63.2 \%$ $(100 / 158)$ up to six months and the vast majority [91.1\% (144/158)] presented reactions within 15 months of medication discharge.

A direct correlation was observed between the number of reactions during treatment and the anti-PGL-1 ELISA serology index at diagnosis $(r=0.2482, p=0.0007)$. Furthermore, an indirect correlation between the number of reactions during the treatment and the Mitsuda test at diagnosis was observed $(r=-0.1545, p=0.0475)$.

An increased probability for the emergence of reactions during treatment was observed in patients with a positive $\mathrm{BI}(\mathrm{OR}=6.39 ; 95 \% \mathrm{CI}: 4.1-10.1)$ or $\mathrm{PCR}(\mathrm{OR}=$ 9.15; 95\% CI: 5.4-15.5) in skin smears, as well as antiPGL-1 seropositivity (ELISA) $(\mathrm{OR}=4.77 ; 95 \% \mathrm{CI}$ : 2.9 7.9) (Table III). Regarding positive laboratory tests at the time of medical discharge, significant $\mathrm{OR}$ were also observed for patients with a positive $\mathrm{BI}(\mathrm{OR}=8.47 ; 95 \%$ CI: 4.7-15.3) or PCR (OR $=6.46$; 95\% CI: $3.4-12.3)$ in skin smears, as well as anti-PGL-1 seropositivity (ELI$\mathrm{SA})(\mathrm{OR}=2.25 ; 95 \% \mathrm{CI}$ : 1.3-3.9) (Table IV).

\section{TABLE I}

Logistic regression analysis of the frequency of epidemiologic characteristics and occurrence of leprosy reactions and no reactions, Uberlândia, state of Minas Gerais, Brazil, 2002-2009

\begin{tabular}{|c|c|c|c|c|c|}
\hline \multirow[b]{2}{*}{ Variables } & Reactions & No reactions & \multicolumn{3}{|l|}{ Total } \\
\hline & $\mathrm{n}(\%)$ & $\mathrm{n}(\%)$ & $\mathrm{n}$ & $95 \% \mathrm{CI}$ & $\mathrm{p}$ \\
\hline \multicolumn{6}{|c|}{ Clinical presentation } \\
\hline I & $0(0)$ & $4(2.1)$ & 4 & - & - \\
\hline TT & $13(5.2)$ & $49(25.9)$ & 62 & $0.01-0.10$ & $<0.001$ \\
\hline BT & $85(33.9)$ & $98(51.9)$ & 183 & $0.06-0.29$ & $<0.001$ \\
\hline $\mathrm{BB}$ & $48(19.1)$ & $12(6.3)$ & 60 & $0.26-1.64$ & 0.036 \\
\hline $\mathrm{BL}$ & $39(15.5)$ & $16(8.5)$ & 55 & $0.16-0.97$ & 0.043 \\
\hline LLS & $5(2)$ & $0(0)$ & 5 & - & - \\
\hline LL & $61(24.3)$ & $10(5.3)$ & 71 & $2.86-11.61$ & $<0.001$ \\
\hline \multicolumn{6}{|c|}{ Operational classification } \\
\hline PB & $49(19.5)$ & $126(66.7)$ & 175 & $3.59-9.82$ & $<0.001$ \\
\hline $\mathrm{MB}$ & $202(80.5)$ & $63(33.3)$ & 265 & - & - \\
\hline \multicolumn{6}{|l|}{ Gender } \\
\hline Male & $172(68.5)$ & $92(48.7)$ & 264 & $1.22-3.32$ & 0.006 \\
\hline Female & 79 (31.5) & $97(51.3)$ & 176 & - & - \\
\hline \multicolumn{6}{|l|}{ Age group } \\
\hline $0-19$ & $4(1.6)$ & $13(6.9)$ & 17 & $0.69-1.36$ & 0.869 \\
\hline $20-39$ & $57(22.7)$ & $43(22.8)$ & 100 & - & - \\
\hline $40-59$ & $131(52.2)$ & $87(46)$ & 218 & - & - \\
\hline$\geq 60$ & $59(23.5)$ & $46(24.3)$ & 105 & - & - \\
\hline Total & $251(57)$ & 189 (43) & 440 & - & - \\
\hline
\end{tabular}

BB: borderline-borderline; BL: borderline-lepromatous; BT: borderline-tuberculoid; CI: confidence interval; I: indeterminate; LL: lepromatous-lepromatous; LLS: subpolar-lepromatous; MB: multibacillary; PB: paucibacillary; TT: tuberculoid. 


\section{TABLE II}

Frequency of patients that developed leprosy reactions during and after multidrug therapy treatment according to the clinical presentation and reaction type, Uberlândia, state of Minas Gerais, Brazil, 2002-2009

\begin{tabular}{ccccc}
\hline \multirow{4}{*}{ Variables } & Type 1 & Mixed & Type 2 & Total \\
\cline { 2 - 5 } & $\mathrm{n}(\%)$ & $\mathrm{n}(\%)$ & $\mathrm{n}(\%)$ & $\mathrm{n}(\%)$ \\
\hline \multicolumn{4}{c}{ During treatment } \\
\hline
\end{tabular}

\begin{tabular}{lcccc}
$\begin{array}{l}\text { Clinical } \\
\text { presentation }\end{array}$ & & & & \\
I & - & - & - & $0(0)$ \\
TT & $9(4.3)$ & - & - & $9(4.3)$ \\
BT & $74(35.1)$ & - & - & $74(35.1)$ \\
BB & $38(18)$ & - & - & $38(18)$ \\
BL & $15(7.1)$ & $5(2.4)$ & $10(4.7)$ & $30(14.2)$ \\
LLS & - & $5(2.4)$ & - & $5(2.4)$ \\
LL & - & - & $55(26.1)$ & $55(26.1)$ \\
\hline Total & $136(64.5)$ & $10(4.7)$ & $65(30.8)$ & $211(100)$ \\
\hline
\end{tabular}

After treatment

Clinical

presentation

\begin{tabular}{lcccc} 
I & - & - & - & $0(0)$ \\
TT & $5(3.2)$ & - & - & $5(3.2)$ \\
BT & $55(34.8)$ & - & - & $55(34.8)$ \\
BB & $31(19.6)$ & - & - & $31(19.6)$ \\
BL & $10(6.3)$ & $6(3.8)$ & $10(6.3)$ & $26(16.5)$ \\
LLS & - & $1(0.6)$ & $2(1.3)$ & $3(1.9)$ \\
LL & - & - & $38(24.1)$ & $38(24.1)$ \\
\hline Total & $101(63.9)$ & $7(4.4)$ & $50(31.6)$ & $158(100)$
\end{tabular}

BB: borderline-borderline; BL: borderline-lepromatous; BT: borderline-tuberculoid; I: indeterminate; LL: lepromatouslepromatous; LLS: subpolar-lepromatous; TT: tuberculoid.

Through the analysis of abnormal blood cell counts and blood biochemistry tests at diagnosis, it was observed that alterations, such as leucocytosis $(\mathrm{OR}=9.97$; 95\% CI: 3.9-25.7), thrombocytopenia (OR $=5.72 ; 95 \%$ CI: 2.3-14.0) and elevated serum LDH $(\mathrm{OR}=2.38 ; 95 \%$ CI: 1.4-4.0), represented significant risks for reactions during treatment (Table V). The main blood count and blood biochemistry alterations that were identified at medication discharge and were potential risk factors for the occurrence of leprosy reactions after MDT treatment were anaemia $(\mathrm{OR}=2.36$; 95\% CI: $1.2-4.5)$, leucocytosis $(\mathrm{OR}=4.14 ; 95 \%$ CI: $1.5-11.6)$ and thrombocytopenia $(\mathrm{OR}=3.70 ; 95 \%$ CI: 1.3-2.2), as listed in Table VI.

\section{DISCUSSION}

Because leprosy reactions are recognised as being closely related to the morbidity and disability associated with disease progression (Foss et al. 2005), several studies have investigated the risk factors for these acute episodes. Co-infections, anti-PGL-1 seropositivity and positive PCR results in skin biopsies have been suggested as predictive variables (Sousa et al. 2007). This study presents new potential markers, providing an improvement in the early identification of leprosy reactions during and after MDT treatment.

At the time of diagnosis, leucocytosis, thrombocytopenia and elevated serum LDH were variables related to type 1 and 2 leprosy reactions during treatment. Leucocytosis and thrombocytopenia, regardless of the leprosy clinical presentation, could indicate an underlying inflammatory process or infection that could trigger the reaction; this finding supports other studies that point to underlying infections as a risk factor for the development of reactions (Pfaltzgraff \& Ramu 1994). LDH, the levels of which increase due to cellular damage, is an enzyme that is present in almost all body tissues. Tissue injury related to nerve damage, regardless of the clinical form, could explain the elevated levels observed, indicating this as a risk factor for both types of leprosy reactions.

The results at medical discharge suggested that abnormalities such as anaemia, leucocytosis and thrombocytopenia may also be risk factors for both types of leprosy reactions after MDT treatment; the blood abnormalities were found in similar proportions in patients from across the clinical spectrum.

The nearly $60 \%$ frequency of patients presenting leprosy reactions during and/or after treatment observed in this study was slightly higher than that found in another study (43.5\%; 290 patients) with a similar sample size (667) (Silva \& Griep 2007).

According to the operational classification distribution, MB patients accounted for more than $80 \%$ of the cases that developed leprosy reactions, a fact that is associated with the patients' bacterial load and the prevalence of borderline individuals (patients immunologically unstable) in endemic areas. In a previous study carried out in India with 2,600 patients who presented leprosy reactions, MB patients represented more than half of the sample, in accordance with our results (Kumar et al. 2004).

An analysis of the clinical spectrum, regardless of the period, revealed that patients who presented the most reactions had LL leprosy, followed by borderlineborderline and borderline-lepromatous leprosy. A previous study reported that LL patients were the most likely patient group to develop reactions during and after discharge, during an evaluation period of five years (Jacob et al. 2008). Less than $50 \%$ of the patients with BT leprosy developed reactions and $\mathrm{BT} / \mathrm{MB}$ patients presented twice the number of reactions than BT/PB patients. The condensed bacterial load, shown in this study through the BI and PCR for M. leprae detection, could justify the higher frequency of reactions among MB patients. As demonstrated, the $\mathrm{BI}$ conferred a greater probability of developing leprosy reactions regardless of the disease period; however, the risk decreased after treatment. 
The OR calculated for the occurrence of leprosy reactions during and after MDT treatment was significant when the BI was positive at both diagnosis and discharge. A previous study from our group demonstrated that there was a positive correlation between $\mathrm{BI} \geq 2$ and a greater number of reactions (Rodrigues et al. 2001). Another study on the association between leprosy reactions and the bacterial load, assessed through the initial

\section{TABLE III}

Distribution of results to laboratory tests at diagnosis, odds ratio (OR) and frequency of leprosy reactions and no reactions during treatment, Uberlândia, state of Minas Gerais, Brazil, 2002-2009

\begin{tabular}{|c|c|c|c|c|c|}
\hline & $\begin{array}{c}\text { Reactions } \\
\text { during treatment }\end{array}$ & No reactions & & & \\
\hline Variables & n $(\%)$ & $\mathrm{n}(\%)$ & OR & $95 \% \mathrm{CI}$ & $\mathrm{p}$ \\
\hline \multicolumn{6}{|c|}{$\mathrm{BI}$ at diagnosis } \\
\hline Positive & $131(64.2)$ & $39(21.9)$ & 6.39 & $4.05-10.09$ & $<0.001$ \\
\hline Negative & $73(35.8)$ & $139(78.1)$ & - & - & - \\
\hline Total & $204(100)$ & $178(100)$ & - & - & - \\
\hline \multicolumn{6}{|c|}{ PCR in skin smears at diagnosis } \\
\hline Positive & $119(77.3)$ & $39(27.1)$ & 9.15 & $5.40-15.49$ & $<0.001$ \\
\hline Negative & $35(22.7)$ & $105(72.9)$ & - & - & - \\
\hline Total & $154(100)$ & $144(100)$ & - & - & - \\
\hline \multicolumn{6}{|c|}{ Anti-PGL-1 ELISA at diagnosis } \\
\hline Positive & $135(73.8)$ & $43(37.1)$ & 4.77 & $2.89-7.87$ & $<0.001$ \\
\hline Negative & $48(26.2)$ & $73(62.9)$ & - & - & - \\
\hline Total & $183(100)$ & $116(100)$ & - & - & - \\
\hline
\end{tabular}

anti-PGL-1: anti-phenolic glycolipid-1; BI: bacterial index; CI: confidence interval; PCR: polymerase chain reaction.

TABLE IV

Distribution of results to laboratory tests at MDT discharge, odds ratio (OR) and frequency of leprosy reactions and no reactions after treatment, Uberlândia, state of Minas Gerais, Brazil, 2002-2009

\begin{tabular}{|c|c|c|c|c|c|}
\hline \multirow[b]{2}{*}{ Variables } & \multirow{2}{*}{$\begin{array}{c}\begin{array}{c}\text { Reactions } \\
\text { after treatment }\end{array} \\
\mathrm{n}(\%)\end{array}$} & \multirow{2}{*}{$\begin{array}{c}\text { No reactions } \\
\mathrm{n}(\%)\end{array}$} & \multirow[t]{2}{*}{ OR } & \multirow[t]{2}{*}{$95 \% \mathrm{CI}$} & \multirow[t]{2}{*}{$\mathrm{p}$} \\
\hline & & & & & \\
\hline \multicolumn{6}{|c|}{$\mathrm{BI}$ at discharge } \\
\hline Positive & $73(60.3)$ & $21(15.2)$ & 8.47 & $4.69-15.28$ & $<0.001$ \\
\hline Negative & $48(39.7)$ & $117(84.8)$ & - & - & - \\
\hline Total & $121(100)$ & $138(100)$ & - & - & - \\
\hline \multicolumn{6}{|c|}{ PCR in skin smears at discharge } \\
\hline Positive & $64(59.3)$ & $18(18.4)$ & 6.46 & $3.41-12.25$ & $<0.001$ \\
\hline Negative & $44(40.7)$ & $80(81.6)$ & - & - & - \\
\hline Total & $108(100)$ & $98(100)$ & - & - & - \\
\hline \multicolumn{6}{|c|}{ Anti-PGL-1 ELISA at discharge } \\
\hline Positive & $71(53.4)$ & $33(33.7)$ & 2.25 & $1.31-3.87$ & 0.004 \\
\hline Negative & $62(46.6)$ & $65(66.3)$ & - & - & - \\
\hline Total & $133(100)$ & $98(100)$ & - & - & - \\
\hline
\end{tabular}

anti-PGL-1: anti-phenolic glycolipid-1; BI: bacterial index; CI: confidence interval; PCR: polymerase chain reaction. 
positive BI, revealed an OR of 2.94; however, the OR was not statistically significant and the study lacked a control group (Brito et al. 2011).

The OR observed for positive PCR results in skin smears at diagnosis and discharge related to the development of leprosy reactions during and after MDT treatment, respectively, presented both relevance and agreement with previous studies demonstrating positive PCR results in skin biopsies as a risk factor for type 1 reactions (Sousa et al. 2007).

A positive correlation was observed between the values of the anti-PGL-1 ELISA serology at diagnosis and the number of leprosy reactions during treatment, reiterating that the increase in specific antibodies against
Mycobacterium leprae is a consequence of humoral immune response activation and increased bacterial load, thus stimulating the development of reactions (BüherSékula et al. 2003). Leprosy reactions are frequently associated with successful treatment, wherein the degradation of killed bacilli causes the release of antigens and stimulates antibody production and cell-mediated immune responses (Spencer et al. 2012). There was a negative correlation between the values of the Mitsuda test at diagnosis, which measures the cell-mediated immune response specific to $M$. leprae and the number of reactions during treatment. When the values of the Mitsuda test increase, the bacterial load decreases, favouring a lower incidence of leprosy reactions (Kar \& Job 2005).

TABLE V

Distribution of results to haematological and biochemical tests at diagnosis, odds ratio (OR) and frequency of leprosy reactions and no reactions during treatment, Uberlândia, state of Minas Gerais, Brazil, 2002-2009

\begin{tabular}{|c|c|c|c|c|c|}
\hline & $\begin{array}{c}\text { Reactions } \\
\text { during treatment }\end{array}$ & $\begin{array}{l}\text { No } \\
\text { reactions }\end{array}$ & OR & $95 \% \mathrm{CI}$ & $\mathrm{p}$ \\
\hline Variables & n $(\%)$ & $\mathrm{n}(\%)$ & & & \\
\hline Anemia & $29(13.7)$ & $16(8.5)$ & 1.80 & $0.94-3.44$ & 0.100 \\
\hline Low haematocrit & $19(9)$ & $7(3.7)$ & 2.69 & $1.10-6.58$ & 0.040 \\
\hline Low haemoglobin & $10(4.7)$ & $9(4.8)$ & 1.10 & $0.43-2.78$ & 0.979 \\
\hline Polycythaemia & $14(6.6)$ & $6(3.2)$ & 2.31 & $0.87-6.18$ & 0.134 \\
\hline Unchanged & $168(79.6)$ & $167(88.4)$ & - & - & - \\
\hline Total & $211(100)$ & $189(100)$ & - & - & - \\
\hline Leukopenia & $0(0)$ & $0(0)$ & - & - & - \\
\hline Leukocytosis & $45(21.3)$ & $5(2.6)$ & 9.97 & $3.86-25.72$ & $<0.001$ \\
\hline Eosinophilia & $20(9.5)$ & $1(0.5)$ & 22.16 & $2.94-167.0$ & $<0.001$ \\
\hline Lymphocytosis & $15(7.1)$ & $2(1.1)$ & 8.31 & $1.87-36.89$ & 0.002 \\
\hline Neutrophilia & $0(0)$ & $2(1.1)$ & - & - & - \\
\hline Targeted high & $10(4.7)$ & $0(0)$ & - & - & - \\
\hline Unchanged & $166(78.7)$ & $184(97.4)$ & - & - & - \\
\hline Total & $211(100)$ & $189(100)$ & - & - & - \\
\hline Thrombocytopenia & $33(15.6)$ & $6(3.2)$ & 5.72 & $2.33-13.98$ & $<0.001$ \\
\hline Plaquetose & $3(1.4)$ & $1(0.5)$ & 3.12 & $0.32-30.28$ & 0.595 \\
\hline Unchanged & $175(82.9)$ & $182(96.3)$ & - & - & - \\
\hline Total & $211(100)$ & $189(100)$ & - & - & - \\
\hline Hypoglycaemia & $8(3.8)$ & $1(0.5)$ & 7.67 & $1.76-2.12$ & 0.056 \\
\hline Hyperglycaemia & $30(14.2)$ & $22(11.6)$ & 1.30 & $0.72-2.36$ & 0.455 \\
\hline Unchanged & $173(82)$ & $166(87.8)$ & - & - & - \\
\hline Total & $211(100)$ & $189(100)$ & - & - & - \\
\hline Elevated serum lactate dehydrogenase & $60(28.4)$ & $27(14.3)$ & 2.38 & $1.43-3.95$ & 0.001 \\
\hline Unchanged & $151(71.6)$ & $162(85.7)$ & - & - & - \\
\hline Total & $211(100)$ & $189(100)$ & - & - & - \\
\hline
\end{tabular}

CI: confidence interval. 
The measurement of the bacillary load through ELISA anti-PGL-1 positivity and its relation to MB leprosy (Büher-Sékula et al. 2003) not only helps to identify MB patients, it also indicates the presence of subclinical infection and can be used as a measure of treatment efficacy (Oskam et al. 2003). In this study, a higher frequency of reactions during treatment than after treatment was observed, which could be influenced by the bacterial clearance and improvement of cell-mediated immunity established by the treatment. These findings were consistent with the results of previous studies that compared patients who developed reactions during treatment and after discharge (Brito et al. 2011).
More than $70 \%$ of the patients developed their first reaction within the first three months after the initiation of treatment, which could be related to the intense release of M. leprae antigens due to the antibacterial action of MDT (Naafs 1994). After treatment, more than $90 \%$ of the patients presented their first reaction within the first 15 months, supporting results from a previous study by our research group that reported that the majority of reactions occurred in the first 12 months (Rodrigues et al. 2001).

The results of the present study showed a predominance of males among the reactive patients and were in agreement with the results of a study of 201 leprosy patients in the city of Recife, state of Pernambuco, Brazil

TABLE VI

Distribution of results to haematological and biochemical tests at multidrug therapy discharge, odds ratio (OR) and frequency of leprosy reactions and no reactions after treatment, Uberlândia, state of Minas Gerais, Brazil, 2002-2009

\begin{tabular}{|c|c|c|c|c|c|}
\hline & $\begin{array}{l}\text { Reactions } \\
\text { after treatment }\end{array}$ & No reactions & OR & $95 \% \mathrm{CI}$ & $\mathrm{p}$ \\
\hline Variables & $\mathrm{n}(\%)$ & $\mathrm{n}(\%)$ & & & \\
\hline Anemia & $29(18.4)$ & $16(8.5)$ & 2.36 & $1.23-4.54$ & 0.013 \\
\hline Low haematocrit & $12(7.6)$ & $7(3.7)$ & 2.23 & $0.85-5.84$ & 0.149 \\
\hline Low haemoglobin & $17(10.8)$ & $9(4.8)$ & 2.46 & $1.06-5.70$ & 0.050 \\
\hline Polycythaemia & $1(0.6)$ & $6(3.2)$ & 0.21 & $0.02-1.82$ & 0.249 \\
\hline Unchanged & $128(81)$ & $167(88.4)$ & - & - & - \\
\hline Total & $158(100)$ & $189(100)$ & - & - & - \\
\hline Leukopenia & $0(0)$ & $0(0)$ & - & - & - \\
\hline Leukocytosis & $16(10.1)$ & $5(2.6)$ & 4.14 & $1.48-11.58$ & 0.007 \\
\hline Eosinophilia & $5(3.1)$ & $1(0.5)$ & 6.47 & $0.74-56.07$ & 0.126 \\
\hline Lymphocytosis & $7(4.4)$ & $2(1)$ & 4.53 & $0.92-22.16$ & 0.089 \\
\hline Monocytosis & $2(1.3)$ & $0(0)$ & - & - & - \\
\hline Neutrophilia & $0(0)$ & $2(1)$ & - & - & - \\
\hline Targeted high & $2(1.3)$ & $0(0)$ & - & - & - \\
\hline Unchanged & 142 (89.9) & $184(97.4)$ & - & - & - \\
\hline Total & $158(100)$ & $189(100)$ & - & - & - \\
\hline Thrombocytopenia & $17(10.8)$ & $6(3.2)$ & 3.70 & $1.29-2.23$ & 0.008 \\
\hline Plaquetose & $2(1.3)$ & $1(0.5)$ & 2.61 & $0.23-29.17$ & 0.820 \\
\hline Unchanged & $139(88)$ & $182(96.3)$ & - & - & - \\
\hline Total & $158(100)$ & $189(100)$ & - & - & - \\
\hline Hypoglycaemia & $6(3.8)$ & $1(0.5)$ & 7.54 & $1.99-2.53$ & 0.073 \\
\hline Hyperglycaemia & $20(12.7)$ & $22(11.6)$ & 1.14 & $0.59-2.18$ & 0.810 \\
\hline Unchanged & $132(83.5)$ & $166(87.8)$ & - & - & - \\
\hline Total & $158(100)$ & $189(100)$ & - & - & - \\
\hline Elevated serum lactate dehydrogenase & $32(20.3)$ & $27(14.3)$ & 1.52 & $0.86-2.67$ & 0.183 \\
\hline Unchanged & $126(79.7)$ & $162(85.7)$ & - & - & - \\
\hline Total & $158(100)$ & $189(100)$ & - & - & - \\
\hline
\end{tabular}

CI: confidence interval 
(Teixeira et al. 2010). It is noteworthy that more than half of the male patients who presented with reactions had MB leprosy, while only one-third of the female patients with reactions were classified as MB leprosy; this result demonstrates a clear association of male gender with $\mathrm{MB}$ leprosy, which may explain the higher number of males among the patients who presented with leprosy reactions.

The patients who presented reactions in this study were predominantly in the age range of 40-59 years, with no significant relationship between this variable and the occurrence of leprosy reactions. Nevertheless, a previous study demonstrated a statistically significant relative risk related to the appearance of leprosy reactions when the patient age was greater than or equal to 40 years (Sousa et al. 2007). This study demonstrated that as age increases, the percentage of MB individuals also increases, which reinforces the idea that as the risk of infection decreases in a community, the age at which people become infected and the proportion of $\mathrm{MB}$ leprosy increase, potentially due to a longer incubation period (Gil Suárez \& Lombardi 1997).

Finally, the results showed that low-cost laboratory tests, performed routinely in most health care facilities, can be used along with other likely prognostic markers, such as anti-PGL-1 serology, for the identification and monitoring of individuals at greater risk of developing leprosy reactions, either during or after MDT treatment. Further evidence will support the implementation of new strategies of prevention, control and management of leprosy reactions, allowing for the timely development of a treatment plan to prevent nerve damage and, therefore, the appearance of the disabling sequelae associated with the stigma of this disease.

\section{ACKNOWLEDGEMENTS}

To the staff of the National Reference Centre for Sanitary Dermatology and Leprosy of Uberlândia, for the support in this research.

\section{REFERENCES}

ADA - American Diabetes Association 2011. Standards of medical care in diabetes - 2011. Diabetes Care 34 (Suppl. 1): S11-S61.

Brito MFM, Ximenes RAA, Gallo MEN, Bührer-Sékula S 2011. Associação entre reação hansênica após alta e a carga bacilar avaliada utilizando sorologia anti-PGL-I e baciloscopia. Rev Soc Bras Med Trop 41: 67-72.

Bührer-Sékula S, Smits HL, Gussenhoven GC, Van Leeuwen J, Amador S, Fujiwar T, Klatser PR, Oskam L 2003. Simple and fast lateral flow test for classification of leprosy patients and identification of contacts with high risk of developing leprosy. J Clin Microbiol 41: 1991-1995.

Foss NT, Souza CS, Goulart IMB, Gonçalves HS, Virmond M 2005. Hanseníase: episódios reacionais. In FB Jatene, Projeto diretrizes, Associação Médica Brasileira/Conselho Federal de Medicina, Brasília, p. 161-179.

Gil Suárez RE, Lombardi C 1997. Estimado de prevalência de lepra. Hansen Int 22: 31-34.

Goulart IMB, Penna GO, Cunha G 2002. Imunopatologia da hanseníase: a complexidade da resposta imune do hospedeiro ao $M y$ cobacterium leprae. Rev Soc Bras Med Trop 35: 365-375.

Jacob JT, Kozarsky P, Dismukes R, Bynoe V, Margoles L, Leonard M, Tellez I, Franco-Paredes C 2008. Five-year experience with type 1 and type 2 reactions in Hansen disease at a US travel clinic. Am J Trop Med Hyg 79: 452-454.
Kar BR, Job CK 2005. Reversal reaction and Mitsuda conversion in polar lepromatous leprosy: a case report. Lepr Rev 76: 258-262.

Kumar N, Droga S, Kaur I 2004. Epidemiological characteristics of leprosy reactions: 15 years experience from North India. Int $J$ Lepr Other Mycobact Dis 72: 125-133.

Lewis SM, Bain BJ, Bates I 2001. Reference ranges and normal values. In JV Dacie, M Lewis, Practical haematology, 9th ed., Churchill Livingstone, London, 633 pp.

Lockwood DN, Suneetha S 2005. Leprosy: too complex a disease for a simple elimination paradigm. Bull World Health Organ 83: $230-235$.

Lockwood DNJ, Suneetha L, Sagili KD, Chaduvula MV, Mohammed I, Van Brakel W, Smith WC, Nicholls P, Suneetha S 2011. Cytokine and protein markers of leprosy reactions in skin and nerves: baseline results for the north Indian. INFIR cohort. PLoS Negl Trop Dis 5: e-1327.

Motta AC, Furini RB, Simão JC, Vieira MB, Ferreira MA, Komesu MC, Foss NT 2011. Could leprosy reaction episodes be exacerbated by oral infections? Rev Soc Bras Med Trop 44: 633-635.

Naafs B 1994. Leprosy reactions. Trop Geogr Med 4: 80-84.

Oskam L, Slim E, Bührer-Sékula S 2003. Serology: recent developments, strengths, limitations and prospects: a state of the art overview. Lep Rev 74: 196-205.

Pfaltzgraff RE, Ramu G 1994. Clinical leprosy. In RC Hasting (ed.), Leprosy, 2nd ed., Churchill Livingstone, New York, p. 237-287.

Ridley DS, Jopling WH 1966. Classification of leprosy according to immunity: a five-group system. Int J Lepr 34: 255-273.

Rodrigues ALP, Almeida AP, Rodrigues BF, Pinheiro CA, Borges DS, Mendonça MLH 2001. Occurrence of late lepra reaction in leprosy patients: subsidies for implementation of a specific care program. Hansen Int 25: 17-25.

Schumann G, Bonora R, Ceriotti F, Férard G, Ferrero CA, Franck PF, Gella FJ, Hoelzel W, Jørgensen PJ, Kanno T, Kessner A, Klauke R, Kristiansen N, Lessinger JM, Linsinger TP, Misaki H, Panteghini M, Pauwels J, Schiele F, Schimmel HG, Weidemann G, Siekmann L 2002. IFCC primary reference procedures for the measurement of catalytic concentrations of enzymes at $37^{\circ} \mathrm{C}$. Part 3: reference procedure for the measurement of catalytic concentration of lactate dehydrogenase. Clin Chem 40: 739-745.

Scollard DM, Smith T, Bhoopat L 1994. Epidemiologic characteristics of leprosy reactions. Int J Lepr Other Mycobact Dis 62: 559-567.

Silva SF, Griep RH 2007. Reação hansênica em pacientes portadores de hanseníase em centros de saúde da área de planejamento do município do Rio de Janeiro. Hansen Int 32: 155-162.

Sousa ALOM, Stefani MMA, Gisner ASP, Costa MB, Rebello PF, Gomes MK, Narahashi K, Gillis TP, Krahenbuhl JL, Martelli CMT 2007. Mycobacterium leprae DNA associated with type 1 reactions in single lesion paucibacillary leprosy treated with single dose rifampin, ofloxacin and minocycline. Am J Trop Med Hyg 77: 829-833.

Spencer JS, Duthie MS, Geluk A, Balagon MF, Kim HJ, Wheat WH, Chatterjee D, Jackson M, Li W, Kurihara JN, Maghanoy A, Mallari I, Saunderson P, Brennan PJ, Dockrell HM 2012. Identification of serological biomarkers of infection, disease progression and treatment efficacy for leprosy. Mem Inst Oswaldo Cruz 107 (Suppl. I): 79-89.

Teixeira MAG, Silveira VM, França ER 2010. Características epidemiológicas e clínicas das reações hansênicas em indivíduos paucibacilares e multibacilares atendidos em dois centros de referência para hanseníase na cidade de Recife, estado de Pernambuco. Rev Soc Bras Med Trop 43: 287-292.

WHO - World Health Organization 2012. Global leprosy situation. Weekly Epidemiol Rec 34: 317-328. 